\title{
Using medical comics to explore challenging everyday topics in medicine: lessons learned from teaching medical humanities
}

\author{
Eva Katharina Masel ${ }^{1}$, Feroniki Adamidis ${ }^{1}$, Anna Kitta ${ }^{1}$, Andreas Gruebl ${ }^{1}$, Matthias Unseld ${ }^{1}$, \\ Philipp Pavelka ${ }^{2}$, Herbert Hans Watzke ${ }^{1}$, Gerhard Zlabinger ${ }^{2}$, Andrea Praschinger $^{2}$ \\ ${ }^{1}$ Department of Internal Medicine I, Division of Palliative Care, Medical University of Vienna, Vienna, Austria; ${ }^{2}$ Teaching Center, Medical \\ University of Vienna, Vienna, Austria \\ Contributions: (I) Concept and design: A Praschinger, EK Masel; (II) Administrative support: None; (III) Provision of literature and research materials: \\ A Gruebl, A Kitta, A Praschinger, EK Masel, M Unseld; (IV) Collection and assembly of data: A Gruebl, A Kitta, A Praschinger, F Adamidis, EK \\ Masel, M Unseld, P Pavelka; (V) Data analysis and interpretation: EK Masel, A Praschinger, F Adamidis, G Zlabinger, HH Watzke, P Pavelka; (VI) \\ Manuscript writing: All authors; (VII) Final approval of manuscript: All authors. \\ Correspondence to: Eva Katharina Masel, MD, PhD, MSc. Department of Internal Medicine I, Division of Palliative Care, Medical University of \\ Vienna, Waehringer Guertel 18-20, Vienna, Austria. Email: eva.masel@gmx.at.
}

Background: Studying medicine requires an extensive acquisition of knowledge, skills and attitudes. At the MedUni Vienna, this wide range of skills is strengthened by discussing aspects of medical humanities $(\mathrm{MH})$ with medical students in their pre-clinical fifth study year. Medical comics (MCs), as a part of MH, offer the possibility to address challenging situations within medical settings through the use of graphic illustrations. Thus, patient stories as well as different perspectives of patients, caregivers, and medical staff can be addressed.

Methods: A total of 506 medical students were randomly assigned to one of three MCs within a blended learning setting via the Moodle online learning platform. The medical students were instructed to reflect on the MC by answering three questions within 1 week. Depending on the MC assigned, the learning objectives were to (I) comprehend demands on a young doctor during a night shift, (II) reflect on a patient examination situation, or (III) recognize patients' physical and/or emotional needs. The word counts of the answers and the time spent online answering the questions in the learning platform were analyzed. This was followed by an analysis in which the answers and their content were rated on a three-point Likert scale (insufficient, sufficient, exceptional). Subsequently, an MH and MCs lecture was held that incorporated the medical students' reflections. After the lecture, a one-minute paper (OMP) survey comprising two questions was conducted on the learning platform.

Results: Of the 506 medical students assigned the online task, 505 completed it. On average, each medical student wrote 110.87 words (SD: 78.54; range, 4.00-602.00) and spent 12.75 minutes (SD: 11.60) on the task. Of all the answers, $84 \%$ were rated as sufficient or exceptional. Two OMP questions: (I) "What was the most important thing you learned today?", and (II) "What questions remain unanswered?" were answered by the medical students. "What was the most important thing you learned today?" was answered by $78 \%(\mathrm{n}=393)$ of the medical students with a profound statement. When asked "What questions remain unanswered?", $85 \%(n=429)$ of the medical students stated that nothing was left unanswered. All the answers included 154 positive and 28 negative comments on the lecture.

Conclusions: The study results indicate that medical students saw great potential in the use of MCs in medical teaching in terms of addressing challenging topics and reflecting on them deeply. This kind of blended learning (a form of learning in which the advantages of face-to-face events and e-learning are combined) successfully showed that medical students can gain a deeper understanding of $\mathrm{MH}$ and be inspired through the use of MCs.

Keywords: Art; education; humanities; medicine; students; teaching 
Submitted Jan 09, 2020. Accepted for publication May 08, 2020.

doi: 10.21037/apm-20-261

View this article at: http://dx.doi.org/10.21037/apm-20-261

\section{Introduction}

Medical humanities ( $M H$ ) can be viewed as an interdisciplinary field at the interface of medicine and humanities, meaning an intersection of hard science and social science (1). Among other things, the goal of $\mathrm{MH}$ is to educate well-rounded doctors who can adapt to the needs of patients of diverse origins and in various situations $(1,2)$. Medical students should acquire humanistic skills that go beyond medical knowledge and hard skills. $\mathrm{MH}$ may encourage students as well as medical staff to acquire soft skills, such as empathy, reflection, and professionalism (3). Humanities offer innovative teaching elements and approaches that can be integrated into medical studies. The promotion of critical, interdisciplinary, and interprofessional discourses on challenging medical topics can expand medical training and competence (4-6).

As a part of $\mathrm{MH}$, graphic medicine and medical comics (MCs) offer an interesting and diverse research field $(7,8)$. MCs can depict challenging topics and encourage a change in perspective so that these difficult subjects can be viewed from different angles. MCs can be used in medical education and teaching to impart soft skills, accelerate selfreflection, sensitize communication skills, and promote observation (9). In medical education, for example, art, film, and literature offer the opportunity to experience different perspectives and to determine that there is more than one answer to a question and more than one view on specific situations (10). Hence, MCs can promote the discussion of complexity and ambiguity. In MCs, drawings are combined with words, sentences, or texts. The variety of topics and different forms of presentation using MCs is applicable to various age groups, interests, and professions.

MCs can be used to address patient stories as well as different perspectives of patients, caregivers, and medical staff (11). Pathography, or patient history from the patient's perspective, is a growing area of study. In this way, knowledge about a clinical picture, the possible ways it can be handled, and the accompanying emotions can be conveyed to doctors or other patients.

MCs are published as monographs in medical journals $(12,13)$. In the early 1940 s, MCs depicted nurses and doctors as heroes (e.g., Florence Nightingale or Robert
Koch). In the mid-19th century, comics began to take the form that we are familiar with today. In the first half of the 20th century, comics developed into a massive phenomenon with genres ranging from fantasy to superheroes.

The term graphic medicine was coined by the British doctor and artist Ian Williams to describe the use of comics in healthcare (14). Since 2007, numerous initiatives have been summarized under this term and can be found at www. graphicmedicine.org. A milestone for MCs was the article "Missed It" published in Annals of Internal Medicine in 2013, which presented a story in pictures on the subject of the fatal consequences of treatment errors (13). The Graphic Medicine Manifesto, published in 2015 as a combination of scientific essays and visual representations, laid the foundation for the establishment of graphic medicine as a new field of research (11).

Because they enable an exchange beyond language and reading skills, the value of MCs is undisputed. Images are often used for patient information purposes. In particular, children and adolescents or people with language barriers can be reached through the medium of MCs.

An example from clinical practice was a study on consent regarding cardiac catheter examination, which was carried out at the Charité Berlin (15). The study demonstrated that a cardiac catheter information sheet presented in comic form improved patients' knowledge and reduced anxiety.

The aim of the present study was to use and examine MCs as teaching elements to address challenging topics. In the fifth year of their six-year study of human medicine at MedUni Vienna, medical students are prepared for their subsequent clinical practice year in which they will spend 48 weeks in clinical rotations. The seminar series of interdisciplinary case conferences during the fifth year of the medical curriculum at MedUni Vienna follows the concept of blended learning. This means that medical students have to take part in an in-person lecture unit and complete thematically coordinated mandatory weekly tasks via an online learning platform.

\section{Methods}

For this study, 506 medical students were randomly assigned to one of three MCs via the Moodle online learning 
Comic 1

[Instruction for students] Consider the situation of a young doctor, edited as a medical comic. Take your time to reflect upon the illustration.

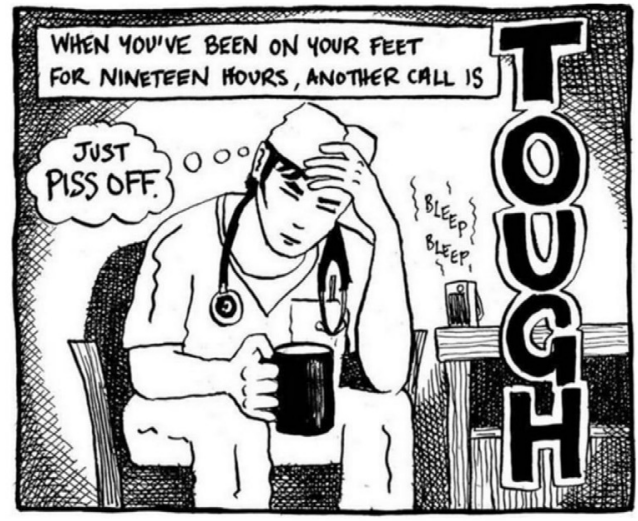

[Task for students] Describe the situation shown in the comic. What other options would the young doctor have to react to the call? What kind of coping strategies can you think of to meet the requirements after 19 hours of service?

Williams I (pseudonym Thom Ferrier). Disrepute, 2012

Figure 1 Requirements for young doctors during night work.

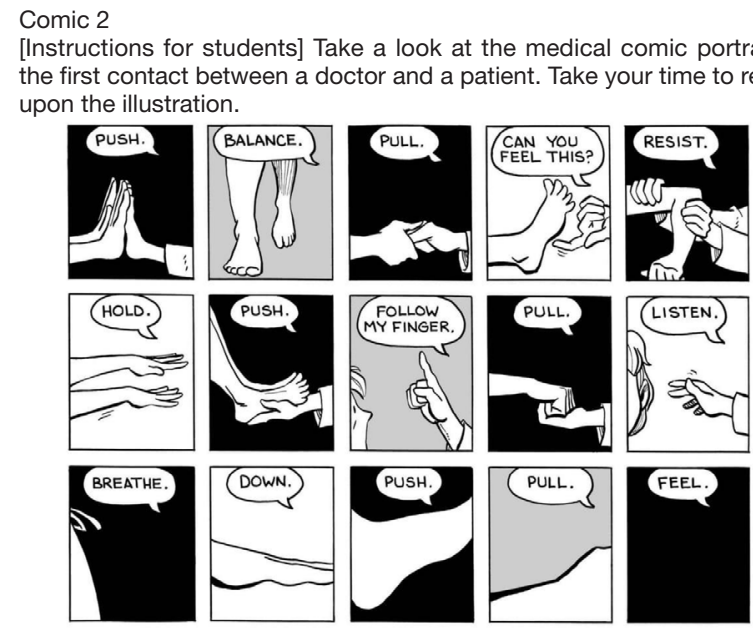

[Task for students] Describe the situation shown in the comic. How is the patient behaving? How might the patient feel? What is the requirement for doctors in this situation?

Fies B. Mom's Cancer, 2006, p18.

Figure 2 Patient examination.

platform. The MCs were selected by a jury consisting of 16 teachers. The medical students had to answer three reflection questions about their respective comic within one week. Learning objectives were to (I) understand
Comic 3

[Instructions for students] Take a look at the medical comic portraying the first contact between a doctor and a patient. Take your time to reflect upon the illustration.

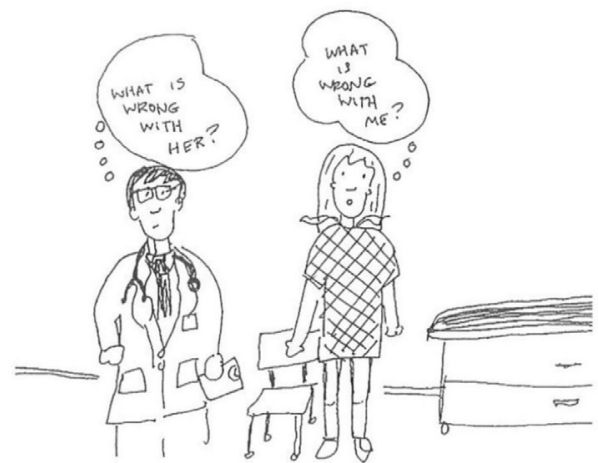

[Task for students] Describe the situation shown in the comic. How is the patient doing? How is the doctor doing? How can a first contact between patient and doctor being pleasant for both sides?

Czerwiec MK, Williams I, Squier SM, Green MJ, Myers KR, Smith ST. Graphic Medicine Manifesto, 2015, p149.

Figure 3 Patients' physical and/or emotional needs.

the requirements for young doctors during night work (Figure 1), (II) think about a patient examination (Figure 2), or (III) recognize patients' physical and/or emotional needs (Figure 3).

Two teachers (EK Masel, A Praschinger) analyzed the word count of the reflections and the time spent online answering the task in the learning platform. This was followed by an analysis in which the answers and their contents were rated on a three-point Likert scale (insufficient, sufficient, and exceptional). Both researchers then compared their rankings of the first 50 answers to ensure comparability at the beginning of the analysis and then continued to rank separately, as their rankings were similar for the first 50 medical students.

The lecturers (EK Masel and A Praschinger) then prepared an $\mathrm{MH}$ and MCs lecture unit on the basis of the medical students' answers that incorporated the medical students' reflections. After the lecture, a one-minute paper (OMP) survey comprising two questions was conducted via the learning platform (16). All procedures performed were in accordance with the ethical standards of the Declaration of Helsinki (as revised in 2013). The current study did not need ethical approval according to the ethics committee of the Medical University of Vienna as no patients were involved in the study. 
Table 1 Data from the learning platform

\begin{tabular}{lcccr}
\hline Online task & Medical students $(\mathrm{n})$ & Technical problems & Average time spent (minutes) & Average word count \\
\hline Comic 1 & 151 & 1 & 15.50 & 83 \\
Comic 2 & 171 & 0 & 13.24 & 112 \\
Comic 3 & 184 & 0 & 12.50 & 79 \\
& 506 & 1 & & \\
\hline
\end{tabular}

Table 2 Three-point Likert scale rating the medical students' reflections

\begin{tabular}{|c|c|c|c|}
\hline Online task & Insufficient (\%) & Sufficient (\%) & Exceptional (\%) \\
\hline Comic 1 & 21.74 & 44.57 & 33.70 \\
\hline Comic 2 & 13.37 & 32.56 & 54.07 \\
\hline Comic 3 & 13.16 & 38.16 & 48.03 \\
\hline
\end{tabular}

\section{Results}

\section{Pre-lecture}

Of the 506 medical students assigned this online task, 505 completed the task. On average, students spent 12.75 minutes on the task (SD: 11.60 ) and wrote 110.87 words (SD: 78.54; range: 4.00-602.00). Of all the answers, $84 \%$ were rated as sufficient or exceptional (Tables 1,2).

\section{Post-lecture}

Two OMP questions: (I) "What was the most important thing you learned today?", and (II) "What questions remain unanswered?" were answered by the medical students. "What was the most important thing you learned today?" was answered by $78 \%(n=393)$ of the medical students with a profound statement. When asked "What questions remain unanswered?", $85 \%(n=429)$ of the medical students stated that nothing was left unanswered. All the answers included 154 positive and 28 negative comments on the lecture. However, $25 \%$ of the answers were not evaluated because they were without content (e.g., characters such as XXX entered via the online platform).

\section{Discussion}

The results of this study indicate that medical students saw great potential in MCs in terms of engaging with challenging topics. Using MCs as a teaching element was well-accepted by the medical students. Furthermore, the time spent on the reflection task as well as the rather high word count of the reflections proved that the medical students were able to profoundly reflect on MCs. This indicates that numerous medical students can understand MH through MCs. Based on the medical students' answers, a lecture about $\mathrm{MH}$ and MCs was held. This lecture constituted a new learning element in the curriculum of medical studies at MedUni Vienna. The concept of using MCs for teaching purposes focused on the ability to change one's perspective, as situations in daily medical practice can be viewed from different angles.

Situations in daily medical practice pose challenges for medical students, medical staff, and-not least—patients and their caregivers. The critical reflection on situations through MCs enabled medical students to question what they would otherwise view as facts. MCs do not primarily serve as a humorous presentation but rather as a visual illustration of challenging topics.

The pictorial expression plays an important role in medicine, where pain, loss, overload, illness, grief, emotional stress, visible and invisible injuries, and much more must be processed and may be difficult to express with words. In previous research, MCs have been studied as a separate art form developed over decades that have proven to be feasible as a teaching method (17-19).

MH supports the development of so-called tacit knowledge, which is difficult to transfer to another person by means of writing it down or verbalizing it (20). MCs can promote visual competence and train the eye, which is essential for daily clinical practice $(8,9)$.

The limitations and strengths of the current study should be mentioned. One limitation is that a qualitative analysis of the medical students' answers was not conducted, which the authors aim to do in a future analysis. Furthermore, it was mandatory for the medical students to answer the MC reflection questions, which might have influenced their answers. This study is lacking a control group; a study 
design with a control group could be useful for further research. The strengths of the study are the large sample size of 505 students and its innovative and novel approach by using MCs as a part of $\mathrm{MH}$ for teaching purposes.

\section{Conclusions}

The results of this study show that by using MCs, medical students were able to reflect on critical clinical situations. The medical students were able to perceive these challenging situations and the resulting needs of patients and their caregivers.

The authors aim to continue the use of $\mathrm{MH}$ and MCs as teaching elements and to conduct mixed methods studies in this research field. The authors further aim to permanently integrate aspects of $\mathrm{MH}$ and MCs into the medical curriculum at MedUni Vienna in order to prepare students for their future job duties. MCs can also serve to address challenging topics such as illness and death in palliative and hospice care and might therefore be useful in teaching palliative care skills (21). In summary, MCs embody a multifaceted, linguistic and visual rhetoric and can be a valuable addition to medical education (22).

\section{Acknowledgments}

The authors wish to thank Monika Himmelbauer, Desiree Koller, and Nina Müller for commenting on the teaching concept. Further, the authors would like to thank Franz Kainberger and Georgios Karanikas for supporting MCs as a novel teaching approach.

Funding: None.

\section{Footnote}

Data Sharing Statement: Available at http://dx.doi. org/10.21037/apm-20-261

Conflicts of Interest: All authors have completed the ICMJE uniform disclosure form (available at http://dx.doi. org/10.21037/apm-20-261). EKM serves as an unpaid editorial board member of Annals of Palliative Medicine Oct 2019 to Sep 2021. GZ reports personal fees from Alexion, personal fees from Bristol-Myers Squibb, personal fees from MedAhead, personal fees from Austrian Chamber of Physicians, personal fees from Pfizer, outside the submitted work. The other authors have no conflicts of interest to declare.
Ethical Statement: The authors are accountable for all aspects of the work and ensuring that questions related to the accuracy or integrity of any part of the work are appropriately investigated and resolved. The study was conducted in accordance with the Declaration of Helsinki (as revised in 2013). The current study did not need ethical approval according to the ethics committee of the Medical University of Vienna, as no patients were involved in the study.

Open Access Statement: This is an Open Access article distributed in accordance with the Creative Commons Attribution-NonCommercial-NoDerivs 4.0 International License (CC BY-NC-ND 4.0), which permits the noncommercial replication and distribution of the article with the strict proviso that no changes or edits are made and the original work is properly cited (including links to both the formal publication through the relevant DOI and the license). See: https://creativecommons.org/licenses/by-nc-nd/4.0/.

\section{References}

1. Thibault GE. Humanism in Medicine: What Does It Mean and Why Is It More Important Than Ever? Acad Med 2019;94:1074-7.

2. Weatherall DJ. The inhumanity of medicine. BMJ 1994;309:1671-2.

3. Wald HS, McFarland J, Markovina I. Medical humanities in medical education and practice. Med Teach 2019;41:492-6.

4. Mangione S, Chakraborti C, Staltari G, et al. Medical Students' Exposure to the Humanities Correlates with Positive Personal Qualities and Reduced Burnout: A Multi-Institutional U.S. Survey. J Gen Intern Med 2018;33:628-34.

5. Kumagai AK. Beyond "Dr. Feel-Good": A Role for the Humanities in Medical Education. Acad Med 2017;92:1659-60.

6. Kumagai AK, Wear D. "Making strange": a role for the humanities in medical education. Acad Med 2014;89:973-7.

7. Green MJ, Myers KR. Graphic medicine: use of comics in medical education and patient care. BMJ 2010;340:c863.

8. Houts PS, Doak CC, Doak LG, et al. The role of pictures in improving health communication: a review of research on attention, comprehension, recall, and adherence. Patient Educ Couns 2006;61:173-90.

9. Naghshineh S, Hafler JP, Miller AR, et al. Formal art 
observation training improves medical students' visual diagnostic skills. J Gen Intern Med 2008;23:991-7.

10. Shapiro J, Rucker L. Can poetry make better doctors? Teaching the humanities and arts to medical students and residents at the University of California, Irvine, College of Medicine. Acad Med 2003;78:953-7.

11. Glazer S. Graphic medicine: comics turn a critical eye on health care. Hastings Cent Rep 2015;45:15-9.

12. Al-Jawad M. Comics are Research: Graphic Narratives as a New Way of Seeing Clinical Practice. J Med Humanit 2015;36:369-74.

13. Green MJ, Rieck R. Missed it. Ann Intern Med 2013;158:357-61.

14. Williams ICM. Graphic medicine: comics as medical narrative. Med Humanit 2012;38:21-7.

15. Brand A, Gao L, Hamann A, et al. Medical Graphic Narratives to Improve Patient Comprehension and Periprocedural Anxiety Before Coronary Angiography and Percutaneous Coronary Intervention: A Randomized Trial.
Ann Intern Med 2019;170:579-81.

16. Cantillon P. Teaching large groups. BMJ 2003;326:437.

17. Lippell S. Creativity and medical education. Med Educ 2002;36:519-21.

18. Bardes CL, Gillers D, Herman AE. Learning to look: developing clinical observational skills at an art museum. Med Educ 2001;35:1157-61.

19. Reynolds RC, Carson RA. Editorial: The place of humanities in medical education. J Med Educ 1976;51:142-3.

20. Walker AM. Tacit knowledge. Eur J Epidemiol 2017;32:261-7.

21. Czerwiec MK, Huang MN. Hospice Comics: Representations of Patient and Family Experience of Illness and Death in Graphic Novels. J Med Humanit 2017;38:95-113.

22. Peterkin A. Curating the medical humanities curriculum: twelve tips. Med Humanit 2016;42:147-8.

Cite this article as: Masel EK, Adamidis F, Kitta A, Gruebl A, Unseld M, Pavelka P, Watzke HH, Zlabinger G, Praschinger A. Using medical comics to explore challenging everyday topics in medicine: lessons learned from teaching medical humanities. Ann Palliat Med 2020;9(4):1841-1846. doi: 10.21037/apm-20-261 